\title{
ROLE OF DIAGNOSTIC LAPAROSCOPY AND HYSTEROSCOPY IN INFERTILITY
}

\author{
Anita Sreekanth ${ }^{1}$
}

${ }^{1}$ Associate Professor, Department of Obstetrics and Gynaecology, Shanthiram Medical College.

\section{ABSTRACT}

\section{BACKGROUND}

The aim of the study is to detect the role of diagnostic laparoscopy and hysteroscopy in detecting uterine, ovarian and pelvic pathologies. It should be offered to all infertility cases who have completed a basic infertility evaluation including ovulation studies, ultrasound, ovarian reserve and hysterosalpingogram for the female and semen analysis for the male. It provides direct visualisation of the pelvic organs and more importantly the tubal status as compared to only ultrasonography and HSG. ${ }^{1}$ Minor procedures like PCOD cauterisation, endometrial ablation, adhesiolysis, salpingectomy for hydrosalpinx also help to improve the infertility outcomes. It enhances the ART outcomes also. ${ }^{2}$

\section{MATERIALS AND METHODS}

The retrospective study included 155 infertility women. It was conducted in the Department of Obstetrics and Gynaecology at Nawrosjee Wadia Memorial Hospital, Mumbai from 2002 - 2003. After clinical examination, necessary investigations were done and written consent was taken before doing laparoscopy. Patients were kept fasting for 24 hours before laparoscopy and it was done under general anaesthesia. The data was collected on prescribed proforma and the results were tabulated and percentages calculated to show the results.

\section{RESULTS}

The age of the patients ranged from 20 - 38 yrs. with a mean age of 26 years. The maximum patients had infertile union of 3 - 5 years. Cases of primary infertility were $72 \%$ and of secondary infertility were $28 \%$; $87 \%$ had no menstrual irregularities; $56.8 \%$ patients had abnormal laparoscopic findings and $15 \%$ had abnormal hysteroscopic findings. No tubal pathology was found in $75 \%$ of cases. Tubal pathology was found in $25 \%$ of cases. Of these, bilateral tubal blockage was found in $9 \%$ and unilateral block in $7.7 \%$ cases. In $8.5 \%$ cases, bilateral block with beaded appearance (TB) was found; $15.5 \%$ cases had PCOD, 9.6\% had endometriosis. Pelvic adhesions were found in $18 \%$ patients. Myomas were found in $6.4 \%$ cases. Bicornuate uterus was seen in $1.2 \%$ cases. Uterine hypoplasia was seen in $1.9 \%$ cases; $15 \%$ had abnormal hysteroscopy findings. Asherman's syndrome was found in $0.65 \%$ patients.

\section{CONCLUSION}

Hysteroscopy and laparoscopy are very valuable tools both diagnostically and therapeutically. They should be offered to all patients with infertile union of more than three years, especially unexplained infertility. Cundiff in 1995 reported that pathologic abnormalities were found in $21-68 \%$ of patients with unexplained infertility at the time of diagnostic laparoscopy. ${ }^{3}$ Operative procedures like lysis of adhesions, endometrial ablation, PCOD cauterisation, salpingectomy for hydrosalpinx positively affect the outcome for ART procedures also. Mean prevalence of uterine malformations in general population is approximately $2.3 \%, 5.3 \%$ in infertile patients and 13\% in recurrent pregnancy losses. ${ }^{4}$ Laparoscopy and Hysteroscopy is a safe and cost effective procedure in infertility patients.

\section{KEYWORDS}

Infertility, Hysteroscopy, Laparoscopy.

HOW TO CITE THIS ARTICLE: Sreekanth A. Role of diagnostic laparoscopy and hysteroscopy in infertility. J. Evolution Med. Dent. Sci. 2017;6(32):2590-2596, DOI: 10.14260/Jemds/2017/560

\section{BACKGROUND}

When the population explosion is the most serious threat that man has ever faced, do we have the right to spend solely needed energies and resources to help the infertile become fertile?

Such is the respect for the individual in our culture that the answer is "yes."

Financial or Other, Competing Interest: None.

Submission 29-12-2016, Peer Review 25-01-2017,

Acceptance 03-02-2017, Published 20-04-2017.

Corresponding Author:

Anita Sreekanth,

Associate Professor

Department of Obstetrics and Gynaecology,

Shanthiram Medical College.

E-mail: anitasreekanth123@gmail.com

DOI: $10.14260 /$ jemds $/ 2017 / 560$
Sterility or infertility is still considered largely a gynaecological problem and it is usually the wife who comes to the gynaecologist for help.

Infertility is defined as a couple that has not conceived after 12 months of normal sexual intercourse without contraception. ${ }^{5}$

Subfertility is a relative state of lowered capacity to conceive. ${ }^{6}$

Secondary infertility is the same state, but developing after an initial phase of fertility.

The cause of infertility is broadly classified as male factor, female factor, unknown or combined. During the investigations in the female, it is mandatory to rule out pathology of the genital tract as cause of infertility.

Approximately, $8 \%$ of couples worldwide are suffering from infertility. ${ }^{7}$ 
It is said that the gynaecologist must have his eyes at the end of his fingers so that he can delineate the size, shape and position of the uterus and evaluate the adnexae. The vaginal or bimanual examination requires training and experience and even the trained gynaecologist frequently encounters difficulties in making a diagnosis.

Especially, in cases of infertility where majority of patients do not have any obvious palpable pathology except the blocked tubes, hystero-laparoscopy is of extreme value. Laparoscopy allows the visualisation of uterus, adnexae and tubes without laparotomy and under minimal anaesthesia and discomfort.

Hysteroscopy is used as an adjunct to this and can increase the effectiveness in evaluating uterine factors for reproductive failures.

Today, hystero-laparoscopy has become the most effective technique to make accurate diagnosis to explain the prognosis and choose the modality of treatment.

\section{History}

Investigation of new tools enabled man to gain supremacy over his surroundings. The investigations in late $19^{\text {th }}$ and $20^{\text {th }}$ century by scientists widened the horizon in the field of infertility. ${ }^{8}$

Endoscopes are instruments used for visualisation of interior of body cavities.

\section{A Chronology of development of Modern Laparoscope is Detailed below-}

- 1901- Ott of Petrograd introduced optical inspection of abdominal cavity with patient in Trendelenburg position at $45^{\circ}$ angle through a culdotomy incision. He called it ventroscopy.

- $\quad$ 1902- Kelling of Dresden visualised peritoneal cavity of a dog with a modified cystoscope.

- 1910- First clinically useful laparoscopy (Jacobaeus, Germany). He introduced a trocar before pneumoperitoneum. He utilised the technique chiefly in patients with ascites. The ascitic fluid was removed and air substituted. He reported a study of 45 laparoscopies in 1925.

- $\quad$ 1912- Nordentoeft of Copenhagen photographed pelvic organs of female cadavers with his instrument 'Trocalendoscope.'

- 1920- Orndoff of Chicago, a roentgenologist invented early forms of laparoscope and used it for diagnostic purposes in diseases of abdomen. He considered a pneumoperitoneum prior to insertion of trocar, a prerequisite.

- 1914- Reccavilla of Italy designed an external light source.

- 1924-Zollikofer of Switzerland employed carbon dioxide for pneumoperitoneum, since it was easily and quickly absorbed than air.

- 1929- Kalk reported his experience with 100 laparoscopic examinations and described his own instrument. His system of lenses produced a foroblique system of viewing (1350). He too used a pneumoperitoneum needle.

- 1937- Hope suggested use of peritoneoscopy in differential diagnosis of ectopic gestation and reported 10 cases of ectopic gestation. Other American influential in development of laparoscope included Anderson (1937), Benedict (1938), Meigs (1939) and Beling (1939).

- 1944- Becker introduced culdoscopy. He stated that failure of proper visualisation was usually due to presence of intestinal loops and inability to isolate pelvic organs properly.

- 1946- Raoul palmer developed intrauterine cannula for manipulation of uterus and introduction of dye for testing tubal patency.

- 1952- Cold light was introduced by Fourster and Volmiere.

- 1952- Still photography in laparoscopy came into being.

- 1957- Frangenheim stressed GA, extreme caution in including pneumoperitoneum and avoidance of puncture through a previous laparotomy scar.

- 1962- L-scopic sterilisation by tubal electrocoagulation was adopted by Palmer.

- $\quad$ 1963- Clymen described operative culdoscopy, which he did under local anaesthesia. He not only cauterised endometrial implants, but also performed tubal and ovarian surgery.

- 1965- Semm (Germany) introduced autonomic carbon dioxide pneumo apparatus.

- $\quad$ 1968- Jean and Cohen advocated laparoscopy as a better method than culdoscopy and this has led to a great interest in the procedures around the world.

- 1977- Gomel reported sharp dissection and neosalpingostomy.

- 1869- Hysteroscopic procedures were first described by Pantaleoni.

The refinement of optical B fibreoptic light accessories now allow high resolution and excellent visual documentation by hysteroscopy.

During the 1980s and 90s, gynaecology has shifted heavily to endoscopy as a speciality.

\section{Specific of Instruments used in the Study \\ Laparoscope}

- Hysteroscope.

- $\quad$ Light source- Storz type.

- Needle-Veress.

- Pneumoperitoneum Apparatus- Semm type.

- Sims' speculum, vulsellum, uterine sound, Hegar's dilators, metal cannula, 1\% methylene blue, solution, uterine sound, Witoon's uterine manipulator.

\section{Distension Media (For Hysteroscopy)}

As uterine cavity is a potential space for panoramic view, walls must be separated by a distension media. Medias are C02, Hyskon, Dextran 32\%.

\section{Criteria for Patient's Selection}

With the help of hystero-laparoscopy, the condition of all the pelvic organs may be evaluated at a time. In this study, we have included:

- All patients with primary infertility of duration of one year or more.

- Patients with duration less than 12 months, where patients were more than 30 yrs. or if she had associated pelvic pathology, any palpable mass or any menstrual abnormality. 
- $\quad$ Cases of secondary infertility.

- Husband's semen analysis was done in all patients and if found abnormal husband's treatment was started first.

\section{MATERIALS AND METHODS}

155 cases of infertility admitted in Gynaecology Dept. at NWMH have been studied. The following protocol was observed and adopted.

\section{Selection of Patients}

Both primary and secondary infertility cases were included.

Complete history of husband and wife was taken. Complete medical history, menstrual history, family history and surgical history taken. Clinical examination of the female done. Complete surgical profile done. HSG and hormonal profile done in relevant cases. Husband's semen analysis was done.

\section{Procedure}

Patients given lithotomy position. Post general anaesthesia abdomen and perineum cleaned and draped. Anterior lip of cervix held with vulsellum with speculum in the vagina. After dilating the cervix up to 6.5, hysteroscopy connected to light source was introduced with distension media. As the uterine cavity got distended, systematic review of fundus, tubal ostia and uterine walls and cervical canal done.

Rubin's cannula was passed for uterine manipulation. A stab incision was taken at inferior border of umbilicus. Veress needle introduced. Pneumoperitoneum created. Later $10 \mathrm{~mm}$ trocar and cannula with telescope introduced. Pelvic organs were next visualised. Panoramic view taken. Any pathology of uterus, tubes and ovaries noted. Tubal patency test with methylene blue done. Additional ports were placed under vision and hand instruments were introduced to perform operative laparoscopy for releasing adhesions, ovarian cyst removal, endometriotic cauterisation, PCOD cauterisation and uterine fibroid removal. At the end, the pelvic cavity is lavaged with normal saline.

\section{Tabulation Analysis and Interpretation}

\begin{tabular}{|c|c|c|}
\hline Age Group (Yrs.) & No. of Cases & \% \\
\hline $15-20$ & 11 & 7 \\
\hline $21-25$ & 53 & 34 \\
\hline $26-30$ & 57 & 36 \\
\hline $31-35$ & 25 & 16 \\
\hline 36 and $>$ & 9 & 5.8 \\
\hline Total & $\mathbf{1 5 5}$ & \\
\hline \multicolumn{2}{|c|}{ Table 1. Case Distribution according to Age } \\
\hline
\end{tabular}

In this study, majority of women were in the age group of $26-30(36 \%)$.

\begin{tabular}{|c|c|}
\hline Primary & Secondary \\
\hline $113(72 \%)$ & $42(28 \%)$ \\
\hline \multicolumn{2}{|c|}{ Table 2. Type of Infertility } \\
\hline
\end{tabular}

Out of 155 cases, 113 had primary infertility and 42 had secondary infertility.

\begin{tabular}{|c|c|c|}
\hline & No. of Cases & \% \\
\hline No demonstrable pathology & 129 & $84 \%$ \\
\hline Demonstrable pathology & 23 & $15 \%$ \\
\hline \multicolumn{2}{|c|}{ Table 3. Hysteroscopy Findings (A) } \\
\hline
\end{tabular}

Considering uterine factor, we found that $84 \%$ of cases had normal findings, $15 \%$ had abnormal findings.

\begin{tabular}{|c|c|c|}
\hline & No. of Cases & $\%$ \\
\hline Uterine cavity normal & 129 & $84 \%$ \\
\hline Uterine cavity abnormal & 23 & $15 \%$ \\
\hline Septum & 10 & 6.5 \\
\hline Hypoplastic uterus & 3 & 1.9 \\
\hline Submucous myoma & 5 & 3.2 \\
\hline IU adhesions & 1 & 0.65 \\
\hline Atrophic endometrium & 1 & 0.65 \\
\hline \multicolumn{3}{|c|}{ Table 4. Hysteroscopy Findings (B) } \\
\hline
\end{tabular}

Uterine septum was found in $6.5 \%$ of cases, submucous myoma in $3.2 \%$ of cases, hypoplastic uterus $1.9 \%$ of cases and atrophic endometrium in $0.65 \%$ of cases, Mullerian anomalies were found in $8.4 \%$ of cases.

\begin{tabular}{|c|c|c|c|}
\hline & & No. of Cases & $\%$ \\
\hline I) & No demonstrable pathology & 67 & $43.2 \%$ \\
\hline II) & Demonstrable pathology & 88 & $56.8 \%$ \\
\hline \multicolumn{3}{|c|}{ Table 5. Laparoscopy Findings } \\
\hline
\end{tabular}

Demonstrable Pathology at Laparoscopy

$56.8 \%$ cases of positive findings on scopy are grouped as:

A) General Pelvic Findings (41\%)

\begin{tabular}{|c|c|c|}
\hline & No. of Cases & $\mathbf{\%}$ \\
\hline Genital TB & 8 & $5.1 \%$ \\
\hline Adhesions & 24 & $15.4 \%$ \\
\hline To Mass & 4 & $2.5 \%$ \\
\hline PID & 16 & $10.3 \%$ \\
\hline Endometriosis & 12 & $7.7 \%$ \\
\hline Total & $\mathbf{6 4}$ & $\mathbf{4 1 \%}$ \\
\hline \multicolumn{3}{|c|}{ Table 6 } \\
\hline
\end{tabular}

In the present study, there were 8 cases of genital TB. The overall incidence of pelvic TB was $5 \%$.

\section{B) Uterine Pathology (10.8\%)}

\begin{tabular}{|c|c|c|}
\hline & No. of Cases & \% \\
\hline Uterine Hypoplasia & 3 & $1.9 \%$ \\
\hline Fibroid & 10 & $6.4 \%$ \\
\hline Bicornuate (Partial) & 2 & $1.2 \%$ \\
\hline Arcuate Uterus & 2 & $1.2 \%$ \\
\hline Total & $\mathbf{1 7}$ & $\mathbf{1 0 . 8}$ \\
\hline \multicolumn{3}{|c|}{ Table 7 } \\
\hline
\end{tabular}

$10.8 \%$ cases had uterine pathology. Fibroid was found in $6.4 \%$ of cases, bicornuate uterus in $1.2 \%$ cases, arcuate uterus in $1.2 \%$ of cases and uterine hypoplasia in $1.9 \%$ cases.

C) Ovarian Pathology (22.5\%)

\begin{tabular}{|c|c|c|}
\hline & No. of Cases & \% \\
\hline PCOD & 24 & $15.5 \%$ \\
\hline Streak Ovarian & 1 & $0.6 \%$ \\
\hline Endometriosis & 10 & $6.4 \%$ \\
\hline Total & $\mathbf{3 5}$ & $\mathbf{2 2 . 5 \%}$ \\
\hline \multicolumn{3}{|c|}{ Table 8} \\
\hline
\end{tabular}


$15.5 \%$ cases had PCOD endometriosis in $6.4 \%$ of cases and streak ovaries in $0.6 \%$ of cases.

\section{D) Tubal Pathology (25\%)}

\begin{tabular}{|c|c|c|c|}
\hline Abnormal & Findings & No. of Cases & Percentage \\
\hline \multirow{2}{*}{ Blocked tubes } & Unilateral & 12 & 7.7 \\
\cline { 2 - 4 } & Bilateral & 14 & 9.0 \\
\hline \multirow{2}{*}{ Cornual block } & Unilateral & 2 & \\
\cline { 2 - 4 } & Bilateral & 1 & \\
\hline \multirow{2}{*}{ Hydrosalpinx } & Unilateral & 10 & $6.4 \%$ \\
\cline { 2 - 4 } & Bilateral & 4 & $2.5 \%$ \\
\hline Total & \multicolumn{3}{|c|}{ Table 9 } \\
\hline \multicolumn{4}{|c|}{} \\
\hline
\end{tabular}

The discrepancy in number is due to more than one pathology in some patients.

\section{A) General Pelvic Pathology}

1) Tuberculosis (5\%)

\begin{tabular}{|c|c|}
\hline Beaded tubes with unilateral tubal block & 2 \\
\hline To mass & 3 \\
\hline To mass with unilateral tubal block & 2 \\
\hline Tubercles on uterus and tubes & 1 \\
\hline $\begin{array}{c}\text { Unilateral tubal block with tubercles and } \\
\text { hydrosalpinx }\end{array}$ & 1 \\
\hline Total & $\mathbf{8}$ \\
\hline
\end{tabular}

In the present study, there were 8 cases of genital TB diagnosed by laparoscopy.

The overcall incidence of pelvic TB was $5 \%$.

\section{2) Adhesions (18\%)}

\begin{tabular}{|c|c|c|}
\hline Abnormal Findings & No. of Cases & $\mathbf{\%}$ \\
\hline Peritubal adhesions & 8 & $5.1 \%$ \\
\hline Adhesions to ovaries & 8 & $5.1 \%$ \\
\hline Adhesions to uterus and POD & 11 & $7.0 \%$ \\
\hline Adhesions to tubes and uterus & 6 & $3.8 \%$ \\
\hline Total & $\mathbf{2 8}$ & $\mathbf{1 8 \%}$ \\
\hline
\end{tabular}

In the present series of $18 \%$, patients had adhesions.

5 of those cases had associated evidence of genital Koch's; 10 had evidence of endometriosis and 13 had chronic PID with tubal damages responsible for infertility.

\section{3) Tubo-ovarian Masses (12.7\%)}

\begin{tabular}{|c|c|c|}
\hline & No. of Cases & $\mathbf{\%}$ \\
\hline Tuberculosis & 3 & $1.9 \%$ \\
\hline PID & 2 & $1.2 \%$ \\
\hline
\end{tabular}

\section{4) Endometriosis (9.6\%)}

\begin{tabular}{|c|c|}
\hline Bilateral chocolate cyst & 3 \\
\hline Unilateral chocolate cyst & 1 \\
\hline Endometric spots on ovaries & 6 \\
\hline Endometriotic spots on uterosacrals & 5 \\
\hline Total & $\mathbf{1 5}$ \\
\hline
\end{tabular}

Review of Literature

Hysterolaparoscopy can detect following Causes of Female Infertility in Sequence ${ }^{9}$

1) During hysteroscopy following pathologies were noted which might have caused-

- Infertility.

- Adhesions (Asherman's syndrome).

- Submucosal fibroid.

- Septum.

- Foreign body.

- Chronic endometritis.

2) Laparoscopy can detect following causes of female infertility-

1. Adhesions in pelvic and abdominal cavity.

2. Cul-de-sac - adhesions and endometritis- extent and density.

3. Uterosacral ligaments- scarring and endometriosis.

4. Ovaries- endometriosis/endometriosis.

- Cystic/solid tumours/PCOD.

- Adhesions (with lateral pelvic wall and with ovarian fossa).

- Mobility.

- Tubo-ovarian relationship.

5. Tubes - cornual occlusion.

- Adhesions, rigidly, tortuosity.

- Fimbrial end for size, scarring and agglutination (hydrosalpinx, fimbrial phimosis and adhesions).

Above assessment is carried out concurrent with transcervical injection of diluted methylene blue solution and to note the site of obstruction of tube.

6. Uterus- Features of tuberculosis (Tobacco pouch appearance, distortion of Oviducts, rigid tubes)-

- Any Mullerian structural anomalies.

- Presence of fibroid (size, type, site).

- Uterine size.

- Surface showing adhesions or endometriotic patches.

\section{Complications}

A) Hysteroscopy Complications

Uterine perforation, cervical stenosis and cervical tear.

B) Laparoscopic Complications

Trauma to intestine and omentum, blood vessel injury, omental prolapse, shoulder pain, wound sepsis, surgical emphysema and anaesthesia complications. ${ }^{10}$

\section{Duration of Stay}

Patients with no complications were discharged on the same day. Patients with any surgical procedure were discharged by 3 days.

\section{DISCUSSION}

Laparoscopy enables a direct visualisation of pathology and helps in the management, further prognosis and reevaluation of the results of treatment. 


\section{Fecundity}

The capacity of man, woman or a couple to participate in the production of live child depends on-

a) Age of wife- maximum at 24 and declines at 30 .

b) Age of husband- maximal around $24-25$.

c) Coital frequency.

d) Length of exposure.

Despite an apparent progress in infertility management still there remains-

Approximately $5-10 \%$ of all married couples in whom no apparent cause is found.

The major causes of infertility are-

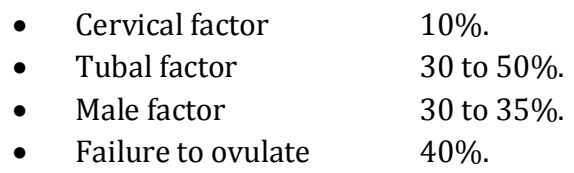

\section{Optimal Time for Laparoscopy}

J F Hulka proposed that once ovulation has been documented by BBT and cervical mucus for 3 cycles and pregnancy is not accomplished, laparoscopy is most appropriate done within 1 - 4 days after presumed ovulation.

In couples undergoing donor insemination, laparoscopy is performed after $4^{\text {th }}$ unsuccessful but well-timed insemination cycle.

Postovulatory laparoscopy gives information on ovulatory status, but at this time the endometrial valve action may interfere with any tubal patency test.

\section{General Pelvic Pathology}

Genital TB is an important cause of infertility in our country. Schaefer differentiates the types of genital tuberculosis ${ }^{11}$

1) Minimal genital tuberculosis, which is symptomless except for sterility and with normal pelvic findings.

2) Advanced and with palpable masses.

Tuberculous tubes are rigid and seem to be fixed to the uterus.

The latent or silent forms are more frequent than acute forms, so that clinical signs and symptoms are usually absent.

Genital TB is almost always secondary to a focus elsewhere in the body.

\section{Gross Appearance in Variable}

1) In early stages there may be no gross changes, but merely slight swelling.

2) Late Stages
A. Pyosalpinx (Tobacco pouch appearance)
B. Chronic interstitial salpingitis
C. Salpingitis isthmica nodosa
D. Hydrosalpinx

Gross lesions are present in tubal mucosa from simple swelling to complete destruction.

The high incidence of sterility is due to block or changes in the tubal mucosa like adhesions between rugal folds, in which sperms are trapped or delayed.

\section{Laparoscopic Appearance}

1) Scattered caseous follicles along the tubes with or without adhesions.
2) Tube is enlarged, congested and rigid.

3) Rosary like distribution or swelling on the tubes -> Nodular salpingitis.

Conception rate even after complete treatment is poor$0.31 \%$.

\section{Adhesions}

Past or present inflammatory disease of the pelvic organs, usually gonococci result in tubal occlusion and chronic endocervicitis which are not grossly recognisable.12

Most grossly palpable chronic intrapelvic adhesions in women of childbearing age are inflammatory in origin.

Although, such tubes may be patent to gas, they may not permit the normal flow of liquids. Laparoscopy is useful not only to diagnose but also to prognosticate.

\section{Endometriosis ${ }^{13}$}

One of 3 patients with unexplained infertility will have endometriosis.

In most, the extent is minimal and cannot be detected by pelvic examinations.

Even minimal endometriosis have been associated with infertility (few pepper spots in cul-de-sac) that respond to treatment.

Fine strands radiating from nodules in peritoneum, the Pouch of Douglas, broad ligament or uterosacrals may be seen.

These strands displace and fix the tubes or their fabricated ends to ovaries, which block tubal motility and ovum pickup. Minimal endometriosis on peritoneal surface can cause infertility.

A mediator of this effect could be the production of prostaglandins by the implants affecting tubal motility, folliculogenesis and corpus luteum function as noted by Meldrum et al, Peterson and Behrman reported a 33\% incidence of endometriosis in infertile patients.

\section{Ovarian Pathology}

\section{1) Stein-Leventhal Syndrome}

Ovaries are enlarged, globular, cystic and on scopy appear pearly white, smooth with thick glistening capsule without any follicular activity.

Such patients have anovulation and on section there is hyperplasia of theca cells, seen mostly in $2^{\text {nd }}$ or $3^{\text {rd }}$ decade of life.

\section{2) Streak Ovaries}

One patient had streak ovaries. Patient had primary amenorrhoea, short stature, underdeveloped breasts and short hair.

Turner's syndrome is a classical syndrome with streak gonads with 45 XO karyotype.

\section{Laparoscopic Findings}

1) Small nodule in place of uterus between bladder and rectum.

2) Two peritoneal folds run from this towards the infundibulopelvic ligaments.

3) In other cases, uterus is hypoplastic and tubes are thin bands.

4) Ovarian hypoplasia. 
5) Occasionally rudimentary fimbriated end of tube present.

\section{Tubal Pathology}

a) Blocked tubes.

b) Hydrosalpinx.

\section{A) Blocked Tubes}

Fertility depends on the presence of normal fallopian tubes in respect to patency, peristalsis and free fimbrial motion.

In majority occlusion is partial.

Aetiology is many-fold. Causes include-
1) PID.
2) Endometriosis.
3) Surgical trauma.

Pelvic inflammatory diseases are gonococcal salpingitis and post-abortal or puerperal sepsis.

Latent tuberculous salpingitis is also responsible for many cases in our country.

The block can be at the fimbrial end, corneal end or at isthmus.

On laparoscopy, they appear as shiny, thin-walled, retortshaped structures. The prognosis of fertility after surgery is poor.

\section{RESULTS}

1) 155 cases of sterility have been studied.

2) No demonstrable pathology was found in $43.2 \%$ and demonstrable pathology was found in $56.8 \%$.

3) Majority of cases were from age group 26 - 30 yrs. with infertile union of 3 - 5 yrs.

4) Pathology affecting uterus were $15 \%$ on hysteroscopy.

5) Pathology affecting tubes were $25 \%$ and $5 \%$ were of tuberculous aetiology.

6) Pathology affecting ovaries was found in $22.5 \%$ of cases.

7) The procedure was carried out under GA.

8) No mortality occurred.

\section{DISCUSSION}

Diagnostic laparoscopy when combined with operative laparoscopy is of therapeutic value.

Laparoscopy in combination with hysteroscopy provides the most complete investigative and therapeutic approach to cervical, uterine of tubal causes of infertility. Even though hysteroscopy is useful as a diagnostic adjunct to traditional methods of evaluation of uterus in infertility, it does not replace laparoscopy rather it complements it.

As compared to only HSG, fallopian tubes can be examined directly in real time under magnification and in its natural habitat under physiological conditions contrary to HSG.

Routine laparoscopy for direct visualisation of the pelvis indicates that 6 out of 10 normal women with unexplained infertility have abnormal findings, which might well be related to their inability to conceive. In most patients, this represents either endometriosis or adhesions involving the pelvic organs.

One of 3 patients with unexplained infertility will have endometriosis. In most, the extent of the endometriosis is minimal and cannot be detected by pelvic examination or suspected from the patient's history.

Treatment of even minimal endometriosis by progestational agents however has been claimed to improve fertility, so that a definitive diagnosis is important in the treatment of the infertility patients.

One of 5 patients with unexplained infertility will have pelvic adhesions, which are so extensive they could easily affect tubo-ovarian motility and ovum pick-up. Such adhesions are not appreciated during routine pelvic examination and furthermore although half of these patients will have a history of previous operation or an inflammatory process, the other half will give no history to suggest a predisposing cause. The pneumoperitoneum defines the adhesions to advantage and occasionally they can be lysed at the time of laparoscopy through a separate instrument designed for this purpose.

The effective therapeutic management of the patient with oligo-ovulation or secondary amenorrhoea has been facilitated by endoscopic inspection of the ovaries. Not only can the diagnosis of polycystic ovarian disease be confirmed, but the occasional patient with such ovaries of normal size can be much more readily identified, in addition the infrequent patient with premature menopause and atrophic ovaries can be identified. More important is the fact that half of these patients demonstrated anatomically normal ovaries, even though showed no evidence of follicular activity. This finding allowed the clinician to undertake stimulation with clomiphene citrate or HMG with added confidence.

Laparoscopy prior to tuboplasty prevented unnecessary operation in 4 of 10 patients. Hence, its routine use is recommended prior to tubal reconstruction.

\section{CONCLUSION}

Diagnostic hysterolaparoscopy proved a very useful method to investigate the infertile women. It helped to diagnose conditions, which were not evident from history or clinical findings in majority of cases.

\section{REFERENCES}

[1] Speroff L, Glass RH, Kase NG. Clinical gynecologic endocrinology \& infertility. $6^{\text {th }}$ edn. Chapter 27. Female Infertility. Lippincott Williams \& Wilkins 1999:1137-90.

[2] Snowden EU, Jarrett JC, Dawood MY. Comparision of diagnostic accuracy of laparascopy, hysteroscopy \& hysterosalphingography in evaluation of female infertility. Fertil Steril 1984;41(5):709-13.

[3] McKenna TJ, Hayes FJ. Recent advances in the diagnosis \& treatment of polycystic ovary syndrome. Recent Advances in Obstetrics \& Gynaecology 1997;19:110-38.

[4] Cundiff G, Carr BR, Marshbum PB. Infertile couples with a normal hysterosalphingogram. Reproductive outcome and its relationship to clinical and laparoscopic findings. J Reprod Med 1995;40(1):1924.

[5] Hammond MG. Evaluation of the infertile couple. Obstet Gynecol Clin North Am 1987;14(4):821-30. 


\section{Jemds.com}

[6] Taylor PJ, Leader A, George RE. Combine hysteroscopy and laparoscopy in the investigations of infertility. In: Siegler AM, Lindemann HJ. (eds). Hysteroscopy principals and practice. Lippincott, Philadelphia 1984.

[7] Yu SL, Yap C. Investigating the infertile couple. Am Acad Med Singapore 2003;32(5):611-3.

[8] Gunning JE. History of laparoscopy. J Reprod Med 1974;12(6):222-6.

[9] Valle RF. Hysteroscopy in the evaluation of female infertility. Am J Obstet Gynecol 1980;137(4):425-31.

[10] Patel DN, Parikh MN, Nanavati MS, et al. Complications of laparoscopy. Asia Oceania J Obstet Gynecol 1985;11(1):87-91.

\section{Original Research Article}

[11] Krishna UR, Sheth SS, Motashaw ND. Place of laproscopy in pelvic inflammatory disease. J Obstet Gynaecol India 1979;29(3):505-10.

[12] Shaw RW. Treatment of endometriosis. In: Stud J. Progress in obstetrics \& gynecology. Vol 9. Churchill Livingstone, Edinburgh London. Melbourne New York \& Tokya, 1991:273-88.

[13] Marconi G, Quintana R. Methylene blue dyeing of cellular nuclei during salphingoscopy, a new in-vivo method to evaluate vitality of tubal epithelium. Hum Reprod 1998;13(12):3414-7. 